Matasha Russell, MD; Mohammad Zare, MD Department of Family and Community Medicine, McGovern Medical School, The University of Texas Health Science Center at Houston

- Matasha.L.Russell@uth tmc.edu

The authors reported no potential conflict of interest relevant to this article.

doi: 10.12788/jfp.0096

\section{How to assess and relieve that perplexing rashless itch}

\section{PRACTICE} RECOMMENDATIONS

> Undertake a diagnostic work-up for systemic causes of pruritus in patients who have a chronic, generalized itch and abnormal findings on physical examination. (c)

> Prescribe gabapentin for its effectiveness in treating pruritus caused by uremic and neurologic itch. (B)

> Consider prescribing one of the bile-acid sequestrants in patients with cholestatic pruritus because these agents can provide moderate relief of the symptom. B

Strength of recommendation (SOR)

A Good-quality patient-oriented evidence

B Inconsistent or limited-quality patient-oriented evidence

C Consensus, usual practice, opinion, disease-oriented evidence, case series
$\mathrm{P}$ ruritus, defined as a sensation that induces a desire to scratch ${ }^{1}$ and classified as acute or chronic (lasting $>6$ weeks), ${ }^{2}$ is one of the most common complaints among primary care patients: Approximately $1 \%$ of ambulatory visits in the United States are linked to pruritus. ${ }^{3}$

Chronic pruritus impairs quality of life; its impact has been compared to that of chronic pain. ${ }^{4}$ Treatment should therefore be instituted promptly. Although this condition might appear benign, chronic pruritus can be a symptom of a serious condition, as we describe here. When persistent pruritus is refractory to treatment, systemic causes should be fully explored.

In this article, we discuss the pathogenesis and management of pruritus without skin eruption in the adult nonpregnant patient. We also present practice recommendations to help you determine whether your patient's pruritus is indicative of a serious systemic condition.

\section{An incomplete understanding} of the pathophysiology of pruritus

The pathophysiology of pruritus is not fully understood. It is generally recognized, however, that pruritus starts in the peripheral nerves located in the dermal-epidermal junction of the skin. ${ }^{5}$ The sensation is then transmitted along unmyelinated slow-conducting $\mathrm{C}$ fibers to the dorsal horn of the spinal cord. ${ }^{5,6}$ There are 2 types of $C$ fibers that transmit the itch impulse ${ }^{6}$ : A histamine-dependent type and a nonhistamine-dependent type, which might explain why pruritus can be refractory to antihistamine treatment. ${ }^{6}$

Once the itch impulse has moved from the spinal cord, it travels along the spinothalamic tract up to the contralateral thalamus. ${ }^{1}$ From there, the impulse ascends to the cerebral cortex. ${ }^{1}$ In the cortex, the impulse triggers multiple areas of the brain, such as those responsible for sensation, motor function, reward, memory, and emotion. ${ }^{7}$

Several chemical mediators have been found to be peripheral 


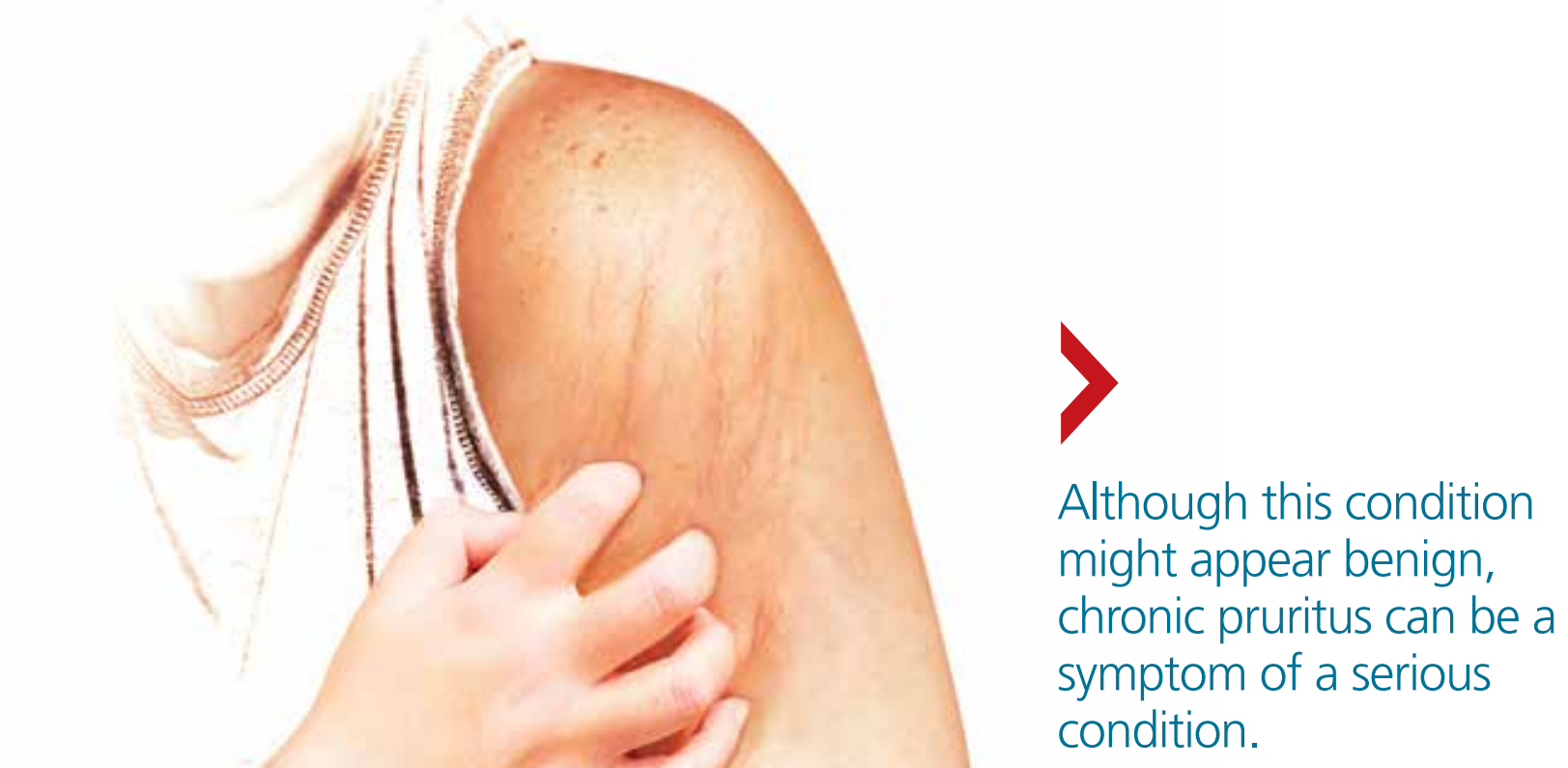

and central inducers of pruritus: histamine, endogenous opioids, substance $\mathrm{P}$, and serotonin. ${ }^{2}$ There are indications that certain receptors, such as mu-opioid receptors and kappa-opioid receptors, are key contributors to itch as well. ${ }^{2}$

\section{A diverse etiology}

The International Forum for the Study of Itch (IFSI) has established 6 main categories of causes of pruritus (TABLE 1) ${ }^{2}$ :

- dermatologic

- systemic

- neurologic

- psychogenic

- mixed

- other.

In this review, we focus on the work-up and management of 3 of those categories: systemic, neurologic, and psychogenic causes of pruritus.

\section{Systemic causes}

Research has shown that $14 \%$ to $24 \%$ of paइ tients who seek the care of a dermatologist for chronic itch without skin lesions have a 흘 systemic illness. ${ }^{8}$

Renal disease. Approximately $40 \%$ of $\frac{3}{2}$ patients with end-stage renal disease who are on hemodialysis or peritoneal dialysis have uremic pruritus. ${ }^{2}$ The itch is mostly generalized but can be pronounced on the back. For most patients, the itch is worse at night, causing a major impact on quality of life. ${ }^{6}$

Liver disease. In hepatic disease, there is often impairment in the secretion of bile, which can lead to cholestatic pruritus. ${ }^{2}$ This condition commonly affects the hands and feet first; later, it becomes generalized. ${ }^{2}$ Cholestatic pruritus can be elicited by tight-fitting clothing. Relief is not achieved by scratching. ${ }^{9}$ This type of itch effects $70 \%$ of patients with primary biliary cirrhosis and $15 \%$ of patients with hepatitis $\mathrm{C}$ infection. ${ }^{9}$

Hematologic disorders. Pruritus is a hallmark symptom of polycythemia rubra vera. Almost $50 \%$ of patients with this disorder report pruritus that occurs after exposure to water $^{9}$; aquagenic pruritus can precede the formal diagnosis of polycythemia rubra vera by years. ${ }^{2}$ It has been speculated that platelet aggregation in this disorder leads to release of serotonin and histamine, which, in turn, causes itch. ${ }^{9}$

Endocrine disorders. Approximately $4 \%$ to $11 \%$ of patients with thyrotoxicosis have pruritus. ${ }^{1}$ It has been suggested that vasodilation, increased skin temperature, and a decreased itch threshold from untreated Graves 
Palpate the liver, spleen, lymph nodes, and thyroid for organomegaly, which could indicate a serious systemic condition as the cause of pruritus.

TABLE 1

\section{IFSI categories of pruritus and its causes ${ }^{2}$}

\begin{tabular}{l|l}
\hline Dermatologic & Neurologic \\
Atopic dermatitis & Brachioradial pruritus \\
Contact dermatitis & Multiple sclerosis \\
Lichen simplex chronicus & Notalgia paresthetica \\
Psoriasis & Postherpetic neuralgia \\
Urticaria & Poststroke \\
Xerosis & Small-fiber polyneuropathy \\
\hline Systemic & Psychogenic \\
Autoimmune disorders (eg, scleroderma) & Anxiety \\
Chronic renal failure & Bipolar disorder \\
Drug-induced & Delusional infestation (delusional parasitosis) \\
Endocrine disorders & Depression \\
Hematologic (eg, polycythemia vera) and & Obsessive-compulsive disorders \\
human immunodeficiency virus infection & \\
Liver disease & \\
Lymphoproliferative disorders & \\
Malignancy & \\
\hline Other & Mixed \\
A cause cannot be found & More than one cause is found \\
\hline
\end{tabular}

IFSI, International Forum for the Study of Itch.

${ }^{a}$ Peripheral and central nervous system disorders.

b Seen in diabetes.

disease might be inciting factors.

I Malignancy. In generalized chronic pruritus without a known cause, strongly consider the likelihood of underlying malignancy ${ }^{8,10}$; for $10 \%$ of these patients, their chronic pruritus is a paraneoplastic sign. Paraneoplastic pruritus is characterized as an itch that predates clinical onset, or occurs early in the course, of a malignancy. ${ }^{9}$ The condition is most strongly linked to cancers of the liver, gallbladder, biliary tract, hematologic system, and skin. ${ }^{11}$

Chronic pruritus affects $30 \%$ of patients with Hodgkin lymphoma. ${ }^{9}$ General pruritus can precede this diagnosis by months, even years. ${ }^{1}$ In Hodgkin lymphoma patients who are in remission, a return of pruritic symptoms can be a harbinger of recurrence. ${ }^{9}$

\section{Neurologic causes}

A recent study found that $8 \%$ to $15 \%$ of patients referred to a dermatology clinic for chronic pruritus without skin eruption had underlying neurologic pathology. ${ }^{12}$ Although the specific mechanisms of neuropathic itch are still poorly understood, it has been theorized that the itch emanates from neuronal damage, which can come from peripheral or central nervous system lesions. ${ }^{9}$

I Brachioradial pruritus. There are divergent theories about the etiology of brachioradial pruritus. One hypothesis is that the condition is caused by cervical nerve-root impingement at the level of C5-C8 that leads to nerve damage ${ }^{2}$; another is that chronic exposure to sunlight causes injury to peripheral cutaneous nerves. ${ }^{2}$ Brachioradial pruritus is localized to the dorsolateral forearm; it can also involve the neck, back, shoulder, upper arm, and chest, unilaterally and bilaterally. This pruritus can be intermittent and become worse upon exposure to sunlight. ${ }^{2}$

I Notalgia paresthetica. This condition might also cause neuropathic pruritus as a 
consequence of nerve impingement. The itch of notalgia paresthesia is located on the skin, medial to the scapular border on the upper or mid-back. ${ }^{2}$ It has been postulated that the itch is caused by nerve entrapment of the posterior rami of spinal nerves arising from T2-T6. ${ }^{9}$ However, another theory suggests that the itch is caused by damage to peripheral nerves. ${ }^{9}$ The itch of notalgia paresthetica can wax and wane. ${ }^{2}$

I Poststroke pruritus. Brain lesions, most often caused by stroke, can cause neuropathic itch. One of the best-known syndromes related to poststroke itch is Wallenberg syndrome (ischemia from a lateral medullary infarction), which typically presents with itch, thermalgic hypoesthesia of the face, cerebellar dysfunction, nausea, and vomiting. ${ }^{7}$

I Shingles. More than one-half of patients who develop postherpetic neuralgia as a consequence of a herpes zoster infection also develop neuropathic pruritus. ${ }^{9}$ It is thought that postherpetic pruritus shares a comparable pathophysiology with postherpetic neuralgia, in which neurons involved in itch stimuli become damaged. ${ }^{7}$

Diabetes mellitus. Pruritus from diabetes can be classified as systemic or neuropathic. Diabetes is one of the most common causes of small-fiber polyneuropathy, which can cause neuropathic pruritus. ${ }^{13}$

I Multiple sclerosis. Central nervous system lesions that affect sensory pathways can lead to neuropathic itch in multiple sclerosis. Patients can have severe episodes of generalized pruritus. It has been hypothesized that the neuropathic itch in multiple sclerosis is induced by activation of artificial synapses in demyelinated areas. ${ }^{2}$

\section{Psychogenic pruritus}

Chronic pruritus can be a comorbidity of psychiatric illness. A retrospective study found that pruritus occurs in $32 \%$ to $42 \%$ of psychiatric inpatients. ${ }^{14}$ Depression, anxiety, bipolar disorders, obsessive-compulsive disorders, somatoform disorders, psychosis, and substance abuse all have a strong link to psychogenic excoriation. ${ }^{15}$ Psychogenic excoriation, which can cause secondary skin lesions, occurs in psychiatric patients who exces-

\section{FIGURE}

\section{Psychogenic excoriations}

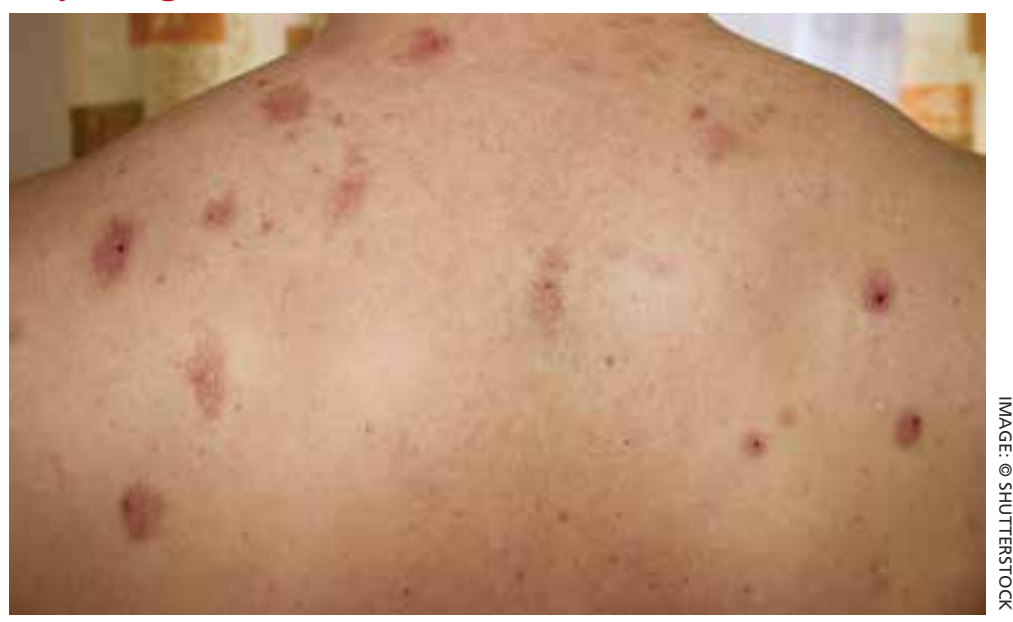

sively pick and scratch normal skin because they perceive an itch sensation or have a delusion of infestation. ${ }^{2}$ Affected skin can be marked by scattered crusted lesions (FIGURE) anywhere on the body that the patient can reach-most commonly, the extremities. ${ }^{2}$

I Delusion of infestation. Patients with a delusion of infestation have a strong belief that their body is infected by some kind of insect or microorganism. ${ }^{16}$ Before a diagnosis of delusion of infestation can be made, other organic causes must be excluded, including withdrawal from such substances as cocaine, amphetamines, and alcohol. ${ }^{16}$ Patients with a delusion of infestation can have, and maintain, a symptomatic response with continuing use of an atypical antipsychotic agent, including risperidone and olanzapine. ${ }^{17}$

\section{Evaluation and diagnostic work-up}

A thorough medical history, review of systems, medication review, social history, and family history are important when evaluating a patient with chronic pruritus. ${ }^{18}$ These items can be valuable in formulating a differential diagnosis, even before a physical examination.

I Physical examination. The physical exam should include detailed inspection of the entire skin and hair ${ }^{18}$; such a comprehensive physical exam can determine whether 
TABLE 2

\section{Initial diagnostic work-up of pruritus ${ }^{18}$}

\begin{tabular}{l}
\hline Blood work \\
Complete blood count (if a hematologic \\
disorder or malignancy is suspected) \\
Comprehensive metabolic profile (if diabetes, \\
liver disease, or renal disease is suspected) \\
Erythrocyte sedimentation rate (if autoimmune \\
disease is suspected) \\
Thyroid-stimulating hormone (if \\
hyperthyroidism is suspected) \\
\hline Serology \\
\hline Hepatitis panel (if liver disease is suspected) \\
Human immunodeficiency virus-1 and -2 \\
antigen/antibody immunoassay \\
\hline Imaging \\
Chest radiography (if lymphoma is suspected) \\
Spinal imaging (such as magnetic resonance \\
imaging; can be a part of a secondary work- \\
up for brachioradial pruritus or notalgia \\
paresthetica)
\end{tabular}

\section{TABLE 3}

\section{Nondrug treatment of pruritus 8}

relief-is

considered

pathognomonic

for brachioradial pruritus.

\begin{tabular}{l} 
Use warm (not hot) water for bathing \\
\hline $\begin{array}{l}\text { Apply emollient to the skin immediately after } \\
\text { bathing }\end{array}$ \\
Use hypoallergenic body products \\
Humidify indoor spaces during the winter \\
Avoid fabrics and other clothing materials that \\
irritate the skin (eg, wool; instead, wear cotton \\
clothing) \\
Wear loose-fitting clothing \\
Avoid vasodilators (eg, caffeine, alcohol, spices, \\
and activities that promote excessive sweating, \\
such as strenuous exercise)
\end{tabular}

the source of the itch is cutaneous. ${ }^{7}$ This, in turn, can help further narrow the differential diagnosis. It is crucial that the physical exam include palpation of the liver, spleen, lymph nodes, and thyroid for organomegaly, ${ }^{8}$ which could indicate a serious systemic condition, such as lymphoma.

The ice-pack sign -in which an ice pack is applied to the pruritic area, the patient experiences immediate relief of pruritus, and the itch returns soon after the ice pack is removed-is considered pathognomonic for brachioradial pruritus. ${ }^{19}$

Chronic pruritus with abnormal findings on the physical exam should prompt an initial work-up. ${ }^{18}$ Also consider an initial workup for a patient with chronic pruritus whose symptom has not been relieved with conservative treatment. ${ }^{18}$

I Laboratory testing. The initial laboratory work-up could include any of the following evaluations: complete blood count, measurement of thyroid-stimulating hormone, comprehensive metabolic panel (liver function, renal function, and the serum glucose level) and the erythrocyte sedimentation rate (TABLE 2). ${ }^{18}$ If warranted by the evaluation and physical exam, blood work can also include serologic studies for human immunodeficiency virus infection and hepatitis. ${ }^{17}$

I Imaging. Chest radiography should be performed if there is suspicion of malignancy, such as lymphoma. ${ }^{7}$ Although brachioradial pruritus and notalgia paresthetica have been postulated to be caused by impingement of spinal nerves, obtaining spinal imaging, such as magnetic resonance imaging, as part of the initial work-up is not recommended; because spinal images might not show evidence of spinal disease, obtaining spinal imaging is not a requirement before treating brachioradial pruritus and notalgia paresthetica. Do consider spinal imaging, however, for patients in whom brachioradial pruritus or notalgia paresthetica is suspected and conservative treatment has not produced a response.

\section{Treatment: Nondrug approaches,} topicals, systemic agents

I Start conservatively. Treatment of pruritus should begin with behavior modification and nonpharmacotherapeutic options (TABLE $3^{8}$ ). Educate the patient that scratching might cause secondary skin lesions; empowering them with that knowledge is sometimes enough to help break the scratching cycling-especially if the patient combines behavior modification with proper skin hydration with an emollient. To prevent secondary skin lesions through involuntary 


\section{TABLE 4}

\section{Topical therapies for pruritus without skin lesions ${ }^{20}$}

\begin{tabular}{|c|c|}
\hline Agent and dosing ${ }^{a}$ & Pruritic condition \\
\hline Emollients and moisturizers & Xerosis \\
\hline $\begin{array}{l}\text { Capsaicin cream } 0.03 \%-0.25 \% \text {; applied bid to qid } \\
\text { Capsaicin } 8 \% \text { patch; single application for } 60 \text { min; may be } \\
\text { repeated every } 90 \mathrm{~d}\end{array}$ & Brachioradial itch, neuropathic itch, uremic itch \\
\hline $\begin{array}{l}\text { Anesthetics (topical) } \\
\text { Compound of ketamine } 1 \%+\text { amitriptyline } 2 \%+ \\
\text { lidocaine } 5 \% \text {; applied bid } \\
\text { Lidocaine patch } 5 \% \text {; applied every } 12 \mathrm{~h} \\
\text { Lidocaine + prilocaine mix } 2.5 \% / 2.5 \% \text {; applied bid } \\
\text { Pramoxine lotion } 1 \% \text {; applied bid }\end{array}$ & $\begin{array}{l}\text { Neuropathic itch, notalgia paresthetica, pretreatment } \\
\text { for capsaicin, uremic itch }\end{array}$ \\
\hline $\begin{array}{l}\text { Calcineurin inhibitors (topical) } \\
\text { Pimecrolimus cream 1\%; applied bid } \\
\text { Tacrolimus ointment } 0.03 \%-0.1 \% \text {; applied bid }\end{array}$ & Psychogenic itch \\
\hline $\begin{array}{l}\text { Phototherapy } \\
\text { Ultraviolet A and B }\end{array}$ & $\begin{array}{l}\text { Notalgia paresthetica, polycythemia vera, psychogenic itch, } \\
\text { uremic itch }\end{array}$ \\
\hline
\end{tabular}

a The drugs listed here are all used to treat pruritus without rash but are not necessarily US Food and Drug Administration-approved for that indication. Consult full prescribing information if you are concerned about the label status of a particular drug.

scratching, consider recommending that lesions be covered with an occlusive dressing or protective clothing. ${ }^{13}$

Stress has been shown to make chronic itch worse; therefore, stress-reduction activities, such as exercise, meditation, and yoga, might be helpful. ${ }^{20}$ For patients in whom pruritus has a psychological component, referral to a psychiatrist or psychologist might be therapeutic.

When a patient complains of severe pruritus at first presentation, consider pharmacotherapy in conjunction with nonpharmacotherapeutic options. Several of the more effective topical therapies for pruritus ${ }^{\mathrm{a}}$ are listed in TABLE $4 .^{20}$ Well-known systemic agents for this purpose are reviewed below and listed in TABLE 5.7

\section{Systemic treatment}

I Antihistamines. A staple in the treatment of pruritus for many years, antihistamines are

$\overline{{ }^{a} \text { Drugs listed in TABLES } 4 \text { and } \mathbf{5} \text { are all used to treat }}$ pruritus without rash but are not necessarily US Food and Drug Administration-approved for that indication. Consult full prescribing information if you are concerned about the label status of a particular drug. not effective for all causes; however, they are effective in treating paraneoplastic pruritus. ${ }^{20}$ First-generation antihistamines, with their sedating effect, can be useful for patients who experience generalized pruritus at night. ${ }^{20}$

Inticonvulsants. Gabapentin and pregabalin are analogs of the neurotransmitter gamma-aminobutyric acid. ${ }^{20}$ This drug class is helpful in neuropathic pruritus specifically caused by impingements, such as brachioradial pruritus and notalgia paresthetica. ${ }^{20}$ In addition, of all systemic therapies used to treat uremic pruritus, gabapentin has, in clinical trials, most consistently been found effective for uremic pruritus. ${ }^{6}$ (Note: Use renal dosing of gabapentin in patients with renal failure.)

I Antidepressants. Selective serotonin reuptake inhibitors (SSRIs; eg, fluvoxamine, paroxetine, and sertraline) might cause itch to subside by increasing the serotonin level, which, in turn, works to decrease inflammatory substances that cause itch. ${ }^{7}$ SSRIs have been used to treat patients with psychogenic pruritus, cholestatic pruritus, and paraneoplastic pruritus. $^{7}$

Tricyclic antidepressants (eg, amitrip- 
Start

conservatively:

Use behavior modification and nonpharmacotherapeutic options for pruritus first.

\section{TABLE 5}

Systemic therapies for pruritus without skin lesions ${ }^{7}$

\begin{tabular}{l|l}
\hline Agents and dosing $^{\mathrm{a}}$ & Pruritic conditions \\
\hline $\begin{array}{l}\text { Antihistamines } \\
\text { First-generation }\end{array}$ & $\begin{array}{l}\text { Nocturnal itch, paraneoplastic itch, systemic } \\
\text { mastocytosis }\end{array}$ \\
- Diphenhydramine $25-50 \mathrm{mg}$ every $4-6 \mathrm{~h}$ prn & \\
- Hydroxyzine $25 \mathrm{mg}$, tid or qid & \\
Second-generation & \\
- Cetirizine $5-10 \mathrm{mg} / \mathrm{d}$ & \\
- Loratadine $10 \mathrm{mg} / \mathrm{d}$ & \\
\hline Anticonvulsants & Neuropathic itch, uremic itch \\
Gamma-aminobutyric acid analogs & \\
- Gabapentin $100-300 \mathrm{mg} / \mathrm{d}$ & \\
- Pregabalin $50-300 \mathrm{mg} / \mathrm{d}$ & \\
\hline
\end{tabular}

\section{Antidepressants}

Selective serotonin reuptake inhibitors
Cholestatic itch, nocturnal itch, paraneoplastic itch, psychogenic itch, uremic itch
- Paroxetine $20-40 \mathrm{mg} / \mathrm{d}$

- Fluvoxamine 25-300 mg/d

- Sertraline $75-100 \mathrm{mg} / \mathrm{d}$

Tricyclics

- Amitriptyline $10-25 \mathrm{mg}$, qd to tid

- Doxepin $10 \mathrm{mg}$, qd or bid

Tetracyclic

- Mirtazapine $15 \mathrm{mg} / \mathrm{d}$

\begin{tabular}{l|l}
\hline Antipsychotics & Delusion of infestation \\
Atypicals & \\
- Olanzapine $2.5-10 \mathrm{mg} / \mathrm{d}$ & \\
\hline $\begin{array}{l}\text { Substance P antagonist } \\
\text { Aprepitant } 80 \mathrm{mg} / \mathrm{d}\end{array}$ & $\begin{array}{l}\text { Brachioradial itch, drug-induced itch, } \\
\text { paraneoplastic itch }\end{array}$ \\
\hline $\begin{array}{l}\text { Opioid-receptor agents } \\
\text { Kappa opioid receptor agonist }\end{array}$ & Cholestatic itch, uremic itch \\
- Nalfurafine $2.5-5 \mathrm{mg} / \mathrm{d}$ & \\
Mu opioid receptor antagonist & \\
\hline $\begin{array}{l}\text { Bile-acid sequestrants } \\
\text { Cholestyramine } 4-6 \mathrm{mg} \text { tid (ie, } 30 \mathrm{~min} \text { before } \\
\text { each of the } 3 \text { daily meals) }\end{array}$ & \\
Ursodiol $13-15 \mathrm{mg} / \mathrm{kg} / \mathrm{d}$ & Cholestatic itch \\
\hline
\end{tabular}

The drugs listed here are all used to treat pruritus without rash but are not necessarily US Food and Drug Administration-approved for that indication. Consult full prescribing information if you are concerned about the label status of a particular drug. 
tyline and doxepin) lessen the itch by antagonizing histamine receptors and through anticholinergic mechanisms. Tricyclics are best used in the treatment of psychogenic and nocturnal itch. ${ }^{7}$

Mirtazapine, a tetracyclic antidepressant, works in patients with uremic pruritus, psychogenic pruritus, cholestatic pruritus, and paraneoplastic pruritus. ${ }^{1}$

I Substance P antagonist. Aprepitant, a neurokinin receptor I antagonist, is a newer agent that inhibits binding of the itch mediator substance $P$ to the neurokinin receptor. The drug has been found helpful in patients with drug-induced, paraneoplastic, and brachioradial pruritus. ${ }^{7}$

I Opioid-receptor agents. Naltrexone, as a mu opioid-receptor antagonist, has shown promise as a treatment for uremic pruritus and cholestatic pruritus. Nalfurafine, a kappa opioid-receptor agonist, is emerging as a possible therapy for uremic pruritus. ${ }^{7}$

I Bile-acid sequestrants. A few small studies have shown that treatment with a bile-acid sequestrant, such as cholestyramine and ursodiol, induces moderate improvement in symptoms in patients with cholestatic pruritus. ${ }^{21}$ JFP

\section{CORRESPONDENCE}

Matasha Russell, MD, Department of Family and Community Medicine, The University of Texas Health Science Center at Houston, McGovern Medical School, 6431 Fannin Street, JJ 324, Houston, TX 77030; Matasha.L.Russell@uth.tmc.edu.

\section{References}

1. Tarikci N, Kocatürk E, Güngör S, et al. Pruritus in systemic diseases: a review of etiological factors and new treatment modalities. ScientificWorldJournal. 2015;2015:803752.
2. Yosipovitch G, Bernhard JD. Clinical practice. Chronic pruritus. N Engl J Med. 2013;368:1625-1634.

3. Silverberg JI, Kantor RW, Dalal P. A comprehensive conceptual model of the experience of chronic itch in adults. Am J Clin Dermatol. 2018;19:759-769.

4. Matterne U, Apfelbacher CJ, Vogelgsang L, et al. Incidence and determinants of chronic pruritus: a population based cohort study. Acta Derm Venereol. 2013;93:532-537.

5. Moses S. Pruritus. Am Fam Physician. 2003;68:1135-1142.

6. Combs SA, Teixeira JP, Germain MJ. Pruritus in kidney disease. Semin Nephrol. 2015;35:383-391.

7. Shevchenko A, Valdes-Rodriguez R, Yosipovitch G. Causes, pathophysiology, and treatment of pruritus in the mature patient. Clin Dermatol. 2018;36:140-151.

8. Reamy BV, Bunt C. A diagnostic approach to pruritus. Am Fam Physician. 2011;84:195-202.

9. Jovanović M. Current concepts of pathophysiology, epidemiology and classification of pruritus. Srp Arh Celok Lek. 2014;142. 106-112.

10. Fett N, Haynes K, Propert KJ, et al. Five-year malignancy incidence in patients with chronic pruritus: a population-based cohort study aimed at limiting unnecessary screening practices. J Am Acad Dermatol. 2014;70:651-658.

11. Larson VA, Tang O, Ständer S, et al. Association between itch and cancer in 16,925 patients with pruritus: experience at a tertiary care center. J Am Acad Dermatol. 2019;80:931-937.

12. Rosen JD, Fostini AC, Chan YH, et al. Cross-sectional study of clinical distinctions between neuropathic and inflammatory pruritus. J Am Acad Dermatol. 2018;79:1143-1144.

13. Oaklander AL. Neuropathic itch. Semin Cutan Med Surg. 2011;30:87-92.

14. Ferm I, Sterner M, Wallengren J. Somatic and psychiatric comorbidity in patients with chronic pruritus. Acta Derm Venereol. 2010;90:395-400.

15. Jafferany M, Davari ME. Itch and psyche: psychiatric aspects of pruritus. Int J Dermatol. 2019;58:3-23.

16. Koo J, Lebwohl A. Psychodermatology: the mind and skin connection. Am Fam Physician. 2001;64:1873-1878.

17. Bewley AP, Lepping P, Freudenmann RW, et al. Delusional parasitosis: time to call it delusional infestation. $\mathrm{Br} J$ Dermatol.2010;163:1-2.

18. Clerc C-J, Misery L. A literature review of senile pruritus: from diagnosis to treatment. Acta Derm Venereol. 2017;97: 433-440.

19. Bernhard JD, Bordeaux JS. Medical pearl: the ice-pack sign in brachioradial pruritus. J Am Acad Dermatol. 2005;52:1073.

20. Sanders KM, Nattkemper LA, Yosipovitch G. Advances in understanding itching and scratching: a new era of targeted treatments [version 1]. F1000Res. 2016;5 F1000 Faculty Rev-2042.

21. Hegade VS, Kendrick SFW, Dobbins RL, et al. Effect of ileal bile acid transporter inhibitor GSK2330672 on pruritus in primary biliary cholangitis: a double-blind, randomised, placebo-controlled, crossover, phase 2a study. Lancet. 2017;389:1114-1123.

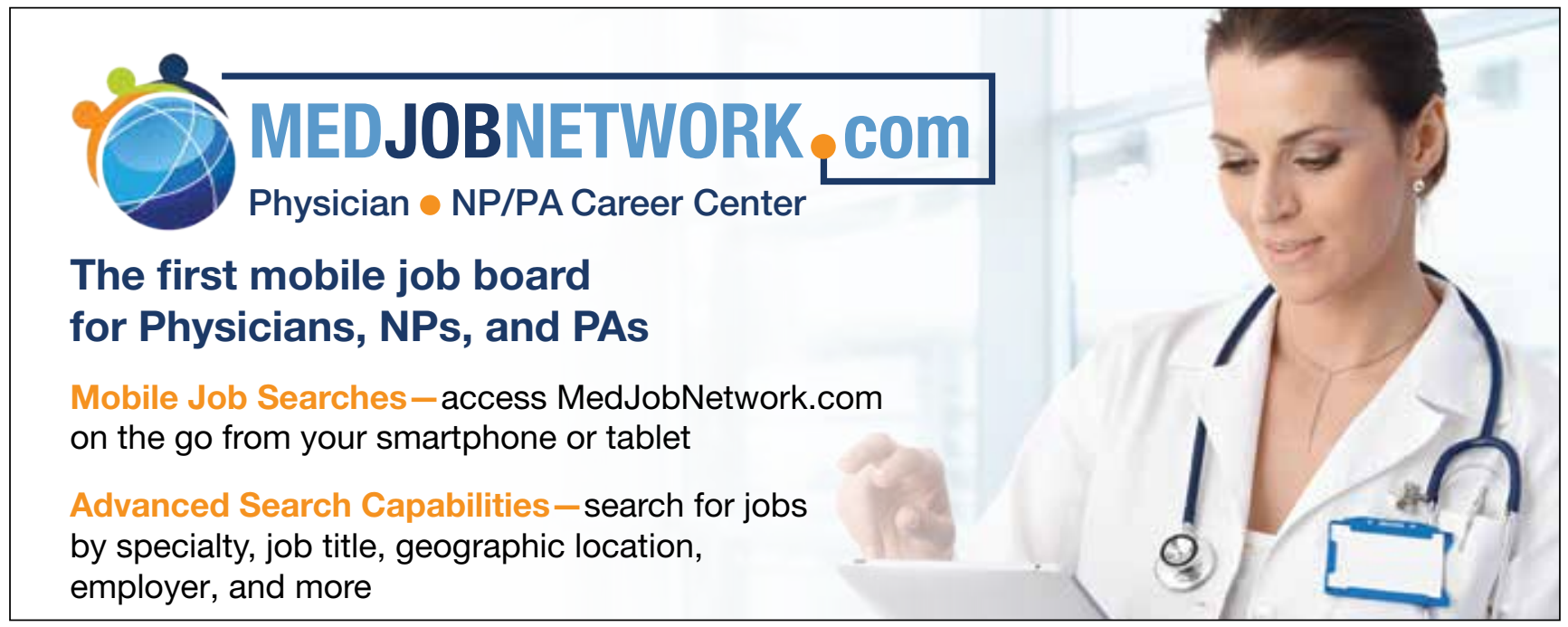

